\title{
Functioning in early and late stages of schizophrenia
}

\author{
Funcionalidade nos estágios inicial e final da esquizofrenia
}

\author{
Leonardo Gazzi Costa, ${ }^{1}$ Raffael Massuda, ${ }^{2}$ Mariana Pedrini, ${ }^{2}$ Ives Cavalcante Passos, ${ }^{2}$ \\ Leticia Sanguinetti Czepielewski, ${ }^{2}$ Elisa Brietzke, ${ }^{3}$ Clarissa S. Gama ${ }^{2}$
}

\begin{abstract}
Introduction: Schizophrenia is frequently associated with a debilitating course and prominent impairment in social and occupational functioning. Although the criteria for classification into stages have not been defined in the literature, illness duration and functioning seem to be good candidates.

Objective: To compare functioning of patients with schizophrenia at different stages of the disease (early vs. late) and healthy sexand age-matched controls.

Methods: This double-blinded, case-controlled study included 79 individuals: 23 patients with schizophrenia diagnosed up to 5 years earlier; 19 patients with schizophrenia diagnosed at least 20 years earlier; and healthy matched controls. Diagnoses were established using the Structured Clinical Interview for Diagnostic and Statistical Manual of Mental Disorders, 4th edition (DSM-IV) Axis I Disorder. Functioning was assessed using the Functioning Assessment Short Test (FAST).

Results: Patients in the early stage had significantly higher scores than healthy controls in total FAST and in autonomy, occupational functioning, cognitive functioning and interpersonal relationships. Individuals in the late stage had significantly poorer functioning than controls in all domains. The comparison of functioning between the two groups of patients revealed no significant differences, except in occupational functioning, in which late stage patients had a poorer performance.

Conclusion: Functioning impairment in schizophrenia tends to remain stable despite illness duration. Therefore, functioning should be effectively assessed at an early stage, as illness duration alone may not be the most reliable criterion to stage patients with schizophrenia.
\end{abstract}

Keywords: Cognition, functioning, psychosis, schizophrenia, staging.

\begin{abstract}
Resumo
Introdução: A esquizofrenia está frequentemente associada a um curso debilitante e a um importante comprometimento no funcionamento social e ocupacional. Embora os critérios para classificação em diferentes estágios ainda não tenham sido definidos, a duração da doença e a funcionalidade têm sido apontadas como bons candidatos.
\end{abstract}

Objetivo: Comparar a funcionalidade de indivíduos com esquizofrenia no estágio inicial e final com controles saudáveis correspondentes em idade e sexo.

Métodos: Neste estudo caso-controle, duplo-cego, foram incluídos 79 pacientes: 23 com diagnóstico de esquizofrenia feito até 5 anos atrás (estágio inicial); 19 diagnosticados há pelo menos 20 anos (estágio final); e controles saudáveis pareados. O diagnóstico foi estabelecido pela Entrevista Clínica Estruturada para Transtornos do Eixo I do Manual Diagnóstico e Estatístico de Transtornos Mentais, $4^{a}$ edição (DSM-IV). A funcionalidade foi avaliada através da escala Teste Breve de Avaliação Funcional (FAST).

Resultados: Os pacientes em estágio inicial tiveram escores significativamente maiores do que controles saudáveis na escala FAST (escore total e domínios autonomia, funcionamento ocupacional, funcionamento cognitivo e relações interpessoais). Os indivíduos em estágio final apresentaram funcionalidade pior que os controles em todos os domínios. A comparação entre os dois grupos não mostrou diferenças, exceto no funcionamento ocupacional, em que os pacientes em estágio final apresentaram um desempenho pior.

Conclusão: $O$ prejuízo da funcionalidade na esquizofrenia tende a permanecer estável ao longo da doença. Portanto, a funcionalidade deve ser avaliada nos estágios iniciais da doença, já que a duração da doença por si só pode não ser o critério mais confiável para definir o estágio de pacientes com esquizofrenia. Descritores: Cognição, funcionalidade, psicose, esquizofrenia, estadiamento.

\footnotetext{
${ }^{1}$ Laboratory of Molecular Psychiatry, National Science and Technology Institute for Translational Medicine (INCT-TM), Hospital de Clínicas de Porto Alegre (HCPA), Universidade Federal do Rio Grande do Sul (UFRGS), Porto Alegre, RS, Brazil. Interdisciplinary Laboratory of Clinical Neuroscience (LINC), Department of Psychiatry, Universidade Federal de São Paulo (UNIFESP), São Paulo, SP, Brazil. ${ }^{2}$ Laboratory of Molecular Psychiatry, INCT-TM, HCPA, UFRGS, Porto Alegre, RS, Brazil. Graduate Program in Medicine: Psychiatry, UFRGS, Porto Alegre, RS, Brazil. ${ }^{3}$ LINC, Department of Psychiatry, UNIFESP, São Paulo, SP, Brazil. Financial support: none.

Submitted Jun 21 2014, accepted for publication Sep 16 2014. No conflicts of interest declared concerning the publication of this article.

Suggested citation: Costa LG, Massuda R, Pedrini M, Passos IC, Czepielewski LS, Brietzke E, et al. Functioning in early and late stages of schizophrenia. Trends Psychiatry Psychother. 2014;36(4):209-213. http://dx.doi.org/10.1590/2237-6089-2014-0028
} 


\section{Introduction}

Functioning is a complex concept involving several different domains, such as the capacity to work, study and live independently, as well as recreational and social capabilities. ${ }^{1}$ Patients with schizophrenia (SZ) have marked impairments in psychosocial functioning across multiple domains: independent living, interpersonal relationships, occupational and educational achievement, recreational enjoyment and sexual activity. ${ }^{2}$ Impairment begins in the early stages (ES) of the disease, and may continue for prolonged periods or result in sustained disability, with high personal suffering and indirect costs to society. ${ }^{2}$

The clinimetric concept of staging in SZ was introduced by Fava \& Kellner in 1993, and an increasing body of research has supported the existence of stages in the longitudinal development of SZ. ${ }^{3}$ Staging systems have been constructed to refine diagnoses and clarify the biological basis of $\mathrm{SZ}$, as well as to support the development of effective treatments that reduce or prevent progression to more advanced SZ phases. ${ }^{4,5}$ However, most studies have concentrated on symptom improvement and illness duration, with much less attention being paid to recovery of psychosocial functioning, although functioning impairment may be more debilitating and long-lasting than the positive symptoms that mark the onset of the illness. ${ }^{6}$ Furthermore, studies have found that psychosocial functioning impairment is not significantly different between patients with a first episode and those with multiple episodes, which suggests that an early and effective psychometric instrument should be used to assess psychosocial functioning in these patients. ${ }^{1,7}$

Optimum care of individuals with SZ is heterogeneous, as it should include a personalized approach best fitted to relieve symptoms, restore functioning and prevent further illness progression. To improve treatment and maximize recovery, ${ }^{2}$ studies should investigate how and if these psychopathological dimensions (symptoms and functioning) correlate.

However, specific psychometric domain scales remain scarce. Most methods to assess functioning are lengthy and do not fully investigate discrete rather than global psychosocial deficits, which severely limits their ability to assess functioning in populations of individuals with SZ. Examining differences in functioning between early stage (ES) and late stage (LS) patients may help identify risk factors for disease progression and potential treatment directions. In sum, knowing in which stage the patient is may help predict disease progression and prognosis, both of which may guide treatment. ${ }^{8}$

The Functioning Assessment Short Test (FAST) is a good psychometric scale to assess functioning in such scenarios. Although not comprehensive, FAST assesses the most relevant functioning domains and may, therefore, provide a reliable index of functioning. Its simplicity, availability and short duration also contribute to its popularity and applicability, in both clinical and research settings. ${ }^{9}$ Despite its potential, FAST has not been used to compare functioning between patients with SZ (ES vs. LS). This study compared psychosocial functioning between patients in ES and LS of overt SZ and a healthy control group. We hypothesized that individuals in the LS group might have worse functioning than healthy controls and individuals in the ES group in all the domains of the FAST scale and in its total score.

\section{Methods}

This study was approved by the Ethics Committee of Hospital de Clínicas de Porto Alegre, RS, Brazil (HCPA) (No. 10-0348). In accordance with the Declaration of Helsinki, all participants were informed about the procedure, and all provided written informed consent before enrollment. Forty-two stable outpatients with SZ and thirty-seven healthy controls matched for age, sex and level of education were recruited. This doubleblinded, case-controlled study included 23 patients in the ES, defined as the first 5 years after diagnosis, 19 at LS, defined as at least 20 years after the diagnosis of SZ, and 19 and 18 matched controls. All patients met the Diagnostic and Statistical Manual of Mental Disorders, 4th edition (DSM-IV) criteria for SZ according to the SemiStructured Interview for DSM-IV (SCID). The control group comprised healthy volunteers with no history of psychiatric disorders and no first-degree relative with a history of a major psychiatric disorder, including dementia or mental retardation. All participants were at least 18 and no older than 60 years old. None had any neurological disease, brain tumor, thyroid disease, severe hepatic disease, severe cardiac disease or any other psychiatric diagnosis.

The psychopathological status of patients with SZ was assessed using the 18-item Brief Psychiatry Rating Scale (BPRS). The BPRS consists of an unstructured interview that includes the following 18 items: somatic concern, psychic anxiety, emotional withdrawal, conceptual disorganization, feelings of self-depreciation and guilt, somatic anxiety, specific motor disturbances, overly inflated self-esteem, depressive mood, hostility, suspiciousness, hallucinations, psychomotor retardation, uncooperativeness, unusual thought content, blunted or inappropriate affect, psychomotor agitation, and disorientation or confusion. The BPRS 
was used to evaluate current symptoms and positive and negative dimensions.

Functioning was assessed using FAST, an instrument primarily developed to assess functional impairment in bipolar disorder ${ }^{10}$ and later structurally validated for SZ. ${ }^{11}$ The Brazilian FAST scale has 24 items to assess five specific domains of functioning: autonomy, occupational functioning, cognitive functioning, financial issues, and interpersonal relationships. The rater asks the patient about areas of difficulty in functioning and defines the score according to the following scale: (0) no difficulty, (1) mild difficulty, (2) moderate difficulty, and (3) severe difficulty.

Final scores are the sum of the scores for individual items in the preceding 15 days. A semi-structured manual is used to ensure uniform understanding of item scoring. ${ }^{11}$

Analysis was performed using the SPSS 18.0. In the LS group, 18 patients were using atypical antipsychotics, which was clozapine in 16 cases; the other four patients were using typical antipsychotics. In the ES group, 14 patients were using atypical antipsychotics, clozapine in seven cases; the other five patients were using typical antipsychotics. Demographic and clinical characteristics were analyzed using descriptive statistics: means and standard deviations, medians and interquartile ranges and percentages, when appropriate. Differences between groups were analyzed using a chi-square, the Mann-Whitney or a $t$ test, as appropriate. The Bonferroni correction was used when multiple pairwise tests were performed. The level of significance was set at $p<0.05$.

\section{Results}

Sample characteristics and comparisons between groups are shown in Table 1 . Despite very different illness duration between the two groups, both had similar scores in BPRS, which indicated that their severity of symptoms was similar. Moreover, there were no differences in dose of antipsychotic in chlorpromazine equivalents (mean daily dose of antipsychotic in $\mathrm{mg}$ of chlorpromazine equivalent \pm standard deviation: $\mathrm{ES}=$ 400 \pm 194.24 ; LS $=624 \pm 203.01$ ).

The analysis of functioning revealed significant difference in total FAST scores of patients in the ES and LS when compared with healthy controls; however, no differences were found when the ES and LS groups were compared to each other. The FAST scores for areas of functioning, such as autonomy, occupational functioning, cognitive functioning, financial issues, interpersonal relationships and leisure time, showed that the LS group had a poorer performance in all areas than controls. Nevertheless, there were no differences in financial issues and leisure time when the ES group was compared with controls. There were differences between ES and LS group scores in occupational functioning, but not in other areas of functioning.

Table 1 - Sample characteristics and comparisons between groups

\begin{tabular}{|c|c|c|c|c|c|c|c|}
\hline & $\begin{array}{c}\text { ES SZ } \\
(n=23)\end{array}$ & $\begin{array}{l}\text { Controls } \\
(n=19)\end{array}$ & $\mathbf{p}$ & $\begin{array}{c}\text { LS SZ } \\
(n=19)\end{array}$ & $\begin{array}{l}\text { Controls } \\
(n=18)\end{array}$ & $\mathbf{p}$ & $\begin{array}{c}\text { ES } x \text { LS } \\
p\end{array}$ \\
\hline Sex (male/female) & $13 / 10$ & $10 / 9$ & $0.523 *$ & $15 / 4$ & $13 / 5$ & $0.714 *$ & - \\
\hline Age in years & $24.70 \pm 4.78$ & $25.32 \pm 5.19$ & $0.692^{+}$ & $47.47 \pm 3.41$ & $46.89 \pm 4.28$ & $0.650^{+}$ & - \\
\hline Years of education & $10.17 \pm 2.57$ & $11.32 \pm 1.99$ & $0.112^{+}$ & $10.26 \pm 3.23$ & $10.39 \pm 3.22$ & $0.906^{+}$ & - \\
\hline Years of disease & $2.52 \pm 1.83$ & - & - & $25.63 \pm 4.66$ & - & - & - \\
\hline $\begin{array}{l}\text { Antipsychotic daily dose, in } \mathrm{mg} \text { of } \\
\text { chlorpromazine equivalents }\end{array}$ & $400 \pm 194.24$ & - & - & $624 \pm 203.01$ & - & - & - \\
\hline BPRS total scores ${ }^{\ddagger}$ & $14(10)$ & - & - & $13(9)$ & - & - & - \\
\hline \multicolumn{8}{|l|}{ FAST scores ${ }^{\ddagger}$} \\
\hline Total & $31(22)$ & $8.5(10.25)$ & $<0.0001^{\mathrm{s}}$ & $34(32)$ & $7(9)$ & $<0.0001^{\S}$ & $0.328^{\S}$ \\
\hline Autonomy & $3(6)$ & $1(2)$ & $0.051^{\S}$ & $5(6)$ & $0.5(2)$ & $<0.0001^{\S}$ & $0.451^{\S}$ \\
\hline Occupational functioning & $10(12)$ & $0(2)$ & $<0.0001^{\S}$ & $15(2)$ & $0.5(2)$ & $<0.0001^{\S}$ & $0.017^{\S}$ \\
\hline Cognitive functioning & $6(7)$ & $3(3)$ & $0.027^{\S}$ & $6(6)$ & $4(5)$ & $0.004^{\S}$ & $1.00^{\S}$ \\
\hline Financial issues & $2(3)$ & $1(2)$ & $1.00^{\S}$ & $2(4)$ & $0(0.25)$ & $0.005^{\S}$ & $1.00^{\S}$ \\
\hline Interpersonal relationships & $6(7)$ & $1(4)$ & $0.001^{\S}$ & $6(9)$ & $0(1.25)$ & $<0.0001^{\S}$ & $1.00^{\S}$ \\
\hline Leisure time & $2(3)$ & $0(2)$ & $0.914^{\S}$ & $3(4)$ & $0(2)$ & $0.007^{\S}$ & $1.00^{\S}$ \\
\hline
\end{tabular}

Data presented as mean \pm standard deviation, unless otherwise stated.

$\mathrm{ES}=$ patients in early stage, defined as up to 5 years after diagnosis of schizophrenia; FAST = Functioning Assessment Short Test; LS = patients in late stage, defined as at least 20 years after diagnosis of schizophrenia; $\mathbf{S Z}=$ schizophrenia.

* Chi-square; ${ }^{+} t$ test; ${ }^{\S}$ Mann-Whitney test with Bonferroni correction for multiple pairwise test.

* Median (interquartile range). 


\section{Discussion}

To our knowledge, this is the first study to assess functioning using the FAST scale and two groups of patients with SZ divided according to illness duration. Our findings provide preliminary evidence of functioning impairment in both the ES and LS groups of patients with SZ when compared with controls. The comparison of the ES and LS groups revealed that, except for occupational functioning, functioning impairment seems to be similar throughout the course of the disease. Our results also revealed that the ES patients had higher FAST scores than controls in the domains of occupational functioning and interpersonal relationships, but not in autonomy. Nevertheless, similar differences were not found in the domains of financial issues and leisure time when the ES group was compared with controls. These results are in accordance with those of a previous study ${ }^{12}$ that found that disability in SZ starts primarily in social and occupational roles and interpersonal relations, and later affects the self-care domain. In addition, the finding that cognitive functioning is already affected in ES patients and that there are no significant differences from LS patients is supported by data reported in other studies, which found that these deficits are already present at the time of the first psychotic episode and remain relatively stable over the course of the illness. ${ }^{13-21}$

In our sample, the mean number of hospitalizations

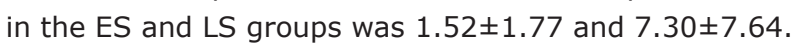
These numbers are in accordance with a study that found that psychosocial functioning impairment was not significantly different between patients with a first psychotic episode and those with multiple episodes. ${ }^{7}$

The fact that no differences were found between the ES and LS groups in most FAST domains may be explained by their similar scores in the assessment of some factors that may potentially affect functioning, such as psychotic symptoms (similar scores in BPRS) and educational attainment. Clinical and functioning improvements are not necessarily concurrent, and functioning impairment may persist in case of symptom remission. ${ }^{10}$

The significant difference between the ES and LS groups in the occupational domain may be associated with the fact that all patients in the LS group were unemployed, and sixteen were retired due to disability. In contrast, there were no retired individuals in the ES group, two were students and two had paying jobs. However, poor work performance in the LS reflects the costs of illness. This finding should guide the definition of interventions for the rehabilitation of these patients and the prevention of impairment in work functioning in the ES.
The findings of this study should be interpreted in light of some limitations. First, the sample size may be small to examine the impact of different predictors of functioning, such as the influence of different groups of symptoms, subtypes of SZ and the impact of medications. In addition, its cross-sectional design does not ensure that both groups are similar in all the variables involved in functioning. At the same time, the study has strengths, such as the inclusion of individuals without any medical and psychiatric comorbidities, which ruled out possible confounders.

\section{Conclusion}

Our findings indicate that illness duration alone is insufficient to classify individuals with SZ into stages because its effect on functioning is only partial. Furthermore, our data confirm previous evidence that functioning impairment tends to remain stable for a long time in most patients with SZ, and suggest that these patients should undergo early functioning assessment using effective psychometric instruments, such as the FAST scale.

\section{Acknowledgements}

The authors thank the Severe Neuropsychiatric Disorders Staging (SENDS) task force for the support provided.

\section{References}

1. Tohen M, Strakowski SM, Zarate C Jr, Hennen J, Stoll AL, Suppes $T$, et al. The McLean-Harvard first-episode project: 6-month symptomatic and functional outcome in affective and nonaffective psychosis. Biol Psychiatry. 2000;48:467-76.

2. González-Ortega I, Rosa A, Alberich S, Barbeito S, Vega P, Echeburúa $E$, et al. Validation and use of the Functioning Assessment Short Test in first psychotic episodes. J Nerv Ment Dis. 2010;198:836-40.

3. Fava GA, Kellner R. Staging: a neglected dimension in psychiatric classification. Acta Psychiatr Scand. 1993;87:225-30.

4. Wood SJ1, Yung AR, McGorry PD, Pantelis C. Neuroimaging and treatment evidence for clinical staging in psychotic disorders: from the at-risk mental state to chronic schizophrenia. Biol Psychiatry. 2011;70:619-25.

5. Scott J, Leboyer M, Hickie I, Berk M, Kapczinski F, Frank E, et al. Clinical staging in psychiatry: a cross-cutting model of diagnosis with heuristic and practical value. Br J Psychiatry. 2013;202:243-5.

6. Mausbach BT, Moore R, Bowie C, Cardenas V, Patterson TL. A review of instruments for measuring functional recovery in those diagnosed with psychosis. Schizophr Bull. 2009;35:307-18.

7. Pinkham $A E$, Penn $D L$, Perkins $D O$, Graham $K A$, Siegel $M$. Emotion perception and social skill over the course of psychosis: a comparison of individuals "at-risk" for psychosis and individuals with early and chronic schizophrenia spectrum illness. Cogn Neuropsychiatry. 2007;12:198-212.

8. Ruiz-Iriondo M, Salaberria K, Echeburúa E. Schizophrenia: analysis and psychological treatment according to the clinical staging. Actas Esp Psiquiatr. 2013;41:52-9. Epub 2013 Jan 1.

9. Rosa AR, Sánchez-Moreno J, Martínez-Aran A, Salamero M, 
Torrent C, Reinares $M$, et al. Validity and reliability of the Functioning Assessment Short Test (FAST) in bipolar disorder. Clin Pract Epidemiol Ment Health. 2007; 3:5.

10. Lee J, Takeuchi H, Fervaha G, Bhaloo A, Powell V, Remington G. Relationship between clinical improvement and functional gains with clozapine in schizophrenia. Eur Neuropsychopharmacol. 2014;24:1622-9. Epub 2014 Aug 12.

11. Zortea K, Magalhaes PV, Rosa AR, Lucena DF, Guimarães $L R$, Francesconi LP. Concurrent validity and reliability of the Brazilian version of the Functioning Assessment Short Test in patients with schizophrenia. Value Health Reg Issues. 2012;1:244-7.

12. de Jong A, Giel R, Slooff CJ, Wiersma D. Social disability and outcome in schizophrenic patients. Br J Psychiatry. 1985;147:631-6.

13. Hoff AL, Kremen WS. Neuropsychology in schizophrenia: an update. Curr Opin Psychiatry. 2003;16:149-55.

14. Hoff AL, Svetina C, Shields G, Stewart J, DeLisi LE. Ten year longitudinal study of neuropsychological functioning subsequent to a first episode of schizophrenia. Schizophr Res. 2005;78:27-34.

15. Addington J, Addington D. Cognitive functioning in first-episode schizophrenia. J Psychiatry Neurosci. 2002;27:188-92.

16. Riley EM, McGovern D, Mockler D, Doku VC, OCeallaigh S, Fannon DG, et al. Neuropsychological functioning in firstepisode psychosis--evidence of specific deficits. Schizophr Res. 2000;43:47-55.
17. Hoff AL, Sakuma M, Wieneke M, Horon R, Kushner M, DeLisi LE. Longitudinal neuropsychological follow-up study of patients with first-episode schizophrenia. Am J Psychiatry. 1999;156:1336-41.

18. Heaton RK, Gladsjo JA, Palmer BW, Kuck J, Marcotte TD, Jeste DV. Stability and course of neuropsychological deficits in schizophrenia. Arch Gen Psychiatry. 2001;58:24-32.

19. Cirillo MA, Seidman LJ. Verbal declarative memory dysfunction in schizophrenia: from clinical assessment to genetics and brain mechanisms. Neuropsychol Rev. 2003;13:43-77.

20. Aleman A, Hijman R, de Haan EH, Kahn RS. Memory impairment in schizophrenia: a meta-analysis. Am J Psychiatry. 1999;156:1358-66.

21. Heinrichs RW, Zakzanis KK. Neurocognitive deficit in schizophrenia: a quantitative review of the evidence. Neuropsychology. $1998 ; 12: 426-45$.

\section{Correspondence:}

Leonardo Gazzi Costa

Rua Pedro de Toledo, $669,3^{\circ}$ andar, Vila Clementino

04039-032 - São Paulo, SP - Brazil

E-mail: leogazzi@yahoo.com.br 